\title{
Smallholder organic farmer's attitudes, objectives and barriers towards production of organic fruits and vegetables in India: A multivariate analysis
}

\author{
Ravi Nandi, Wolfgang Bokelmanna, Vishwanath Gowdru Nithya, Gustavo Dias \\ Institute of Agricultural Economics and Social Sciences, Division of Horticultural Economics, Humboldt University of Berlin, \\ Invaliden Strasse 42,10115, Germany
}

\section{A B S T R A C T}

\begin{abstract}
The Indian organic food sector has experienced important growth during recent years. Despite growth potential, area under organic farming is meager. Indian smallholders $(<2$ ha) are facing challenges to enter and sustain in the organic food sector and benefit from this growth in a sustainable way. In this context, the aim of this paper was to analyze smallholder farmer's attitudes, objectives and barriers towards production of organic fruits and vegetables (F\&V) in South India as well as to identify farmers' profiles based on attitudes and objectives. The source of information used in this study was a field survey carried out during early 2014. The purposive random sampling technique was used to draw the sample $(n=127)$ and the mode of data collection was face-to-face interviews; collected data were analyzed by using descriptive, factor and two-step cluster analysis. The results of factor analysis based on attitudes revealed that five factors including "Market", "Environmental", "Support", Benefit \& Cost" and "Community" factors explained 70.05 per cent of the total variance. Further, factor analysis based on objectives acknowledged the presence of three latent factors including "Economic", "Environmental" and "Sociocultural" factors explaining 77.90 percent of the variance. Similarly, four latent factors were identified based on the factor analysis on sixteen barrier variables, representing "Production", "Marketing", Techno-managerial" and "Economic \& Financial" barriers explained 68.52 percent of the variance. Further, three clusters emerged on these attitudes and objective factor scores representing, $45 \%, 23.6 \%$ and $31.50 \%$ of the sample size. All three clusters have different levels of orientation to produce organically on the basis of each factor. The "Market and economic" factors are most important in two clusters followed by "Government support" and "Environmental" factors; a third cluster was fairly indifferent towards the organic F\&V production. Results of this research have implications for policy makers, marketing professionals towards organic agriculture development by calibrating appropriate strategies to promote organic farming and enabling supporting environment in south India.
\end{abstract}

Keywords: Organic Farming; Attitudes; Barriers; Multivariate analysis; India

\section{INTRODUCTION}

Global demand for organic food products has remained robust and was estimated to have reached 63 billion US Dollars in 2011; an increase by four billion in comparison to 2010. Most of the sales are from the US market, which has the largest organic food \& drink market in the world. The overwhelming majority, i.e. ninety seven per cent of the sales takes place in the United States and European Union with a increasing commodity import from developing countries (Willer et al., 2013). However, the speedy rise of both supermarket chains and an urban upper middleclass consumer segment in the Industrialized Countries of the South (Reardon and Berdegue, 2002) has recently brought about an important expansion of the domestic market in these countries (Sirieix et al., 2011). International Organizations such as the FAO or the IFAD acknowledged huge opportunity for smallholder farmers specifically to take advantage of the globally increase in organic food demand (Scialabba, 2007). Many scholarly researches showed that organic farming has the potential to provide smallholders with access to markets with higher profits while creating new partnerships along the whole value chain, strengthening their self-confidence and improving their livelihood (Shah et al., 2005; Kilcher, 2007; Bolwig et al., 2009). From a general point of view, researchers have highlighted that smallholder in developing countries, who are often economically marginalized and with low

\footnotetext{
*Corresponding author:

Ravi Nandi, Institute of Agricultural Economics and Social Sciences, Division of Horticultural Economics, Humboldt University of Berlin, Robert Koch-Platz 4, D-10099, Germany. E-mail: nandi999hu@gmail.com
} 
educational and are facing many challenges to enter the organic sector and to benefit from it. Problems such as decreasing incomes during the conversion period and high costs for certification are major constraints, particularly when no specific subsidies exist for organic production (Egelyng, 2009). In addition, structural barriers such as access to credit facility, difficulties in creating reliable market linkages and a lack of knowledge about organizational management are also considered to be important barriers (Nordlund and Egelyng, 2008; Veisi et al., 2013).

The Indian organic food sector has a great potential to produce almost a wide variety of organic products due to its multiple agro climatic conditions at various regions. In many parts of the country, the inherited tradition of organic farming is an added advantage. This holds promise for the organic producers to tap the market which is growing steadily domestically due a connection with the dynamism of the export market. India produced around 1.34 million MT of certified organic products and exported 135 products last year (2012-13) with total volume of $165262 \mathrm{MT}$. The organic products export realization was around 374 million US \$ registering a $4.38 \%$ growth over the previous year. Organic products are exported to EU, US, Switzerland, Canada, South East Asian countries and South Africa (APEDA, 2014). By its turn, the domestic market for organic products is at an early phase of its development. Currently, fresh produces (fruits and vegetables) are the highest demanded organic food categories in the country. Indian agriculture is the home of small and marginal farmers $(80 \%)$ and there are about 121 million agricultural holdings in India, out of which 99 million were small and marginal. Therefore, the future of organic agriculture growth and food security in India is connected to the fate of this category of actors (Dev, 2012). The smallholder farmers contribute around $70 \%$ to the total production of vegetables, $55 \%$ to fruits against their share of $44 \%$ in land area in the country (Dev, 2012).

Presently, there are 0.55 million organic producers cultivating 1.10 million hectare in India (Willer et al., 2013). The area under organic farming is relatively small as compared to total cultivable area in the country. Following the presented figures and current scenario and given the early phase of India's organic sector some reflections on this context are at hand. Accordingly, one may reach the argument pressuring for a greater focus on small and marginal farmers in order to tackle the challenge of how to convert more and more productive areas into organic farming. In this context, the aim of the present work was to analyze the attitudes of smallholder farmers towards the adoption of organic fruits and vegetables $(\mathrm{F} \& \mathrm{~V})$ farming. Furthermore it identifies segments of smallholder farmers in accordance with their attitudes and their relationship with farming objectives and the degree of orientation of farmers towards organic $\mathrm{F} \& \mathrm{~V}$ production. Further, barriers towards the adoption and development of organic F\&V farming are assessed. This research article is part of the doctoral research project being conducted in the department of agricultural economics, Humboldt University of Berlin, Germany.

\section{MATERIAL AND METHODS}

\section{Selection and description of the sample}

The research was conducted in Karnataka state, in India, the first state in the country to implement an organic farming policy. The source of information used in this study was mainly obtained from personal interviews based on the structured questionnaires, carried out on a sample of 127 organic smallholders. A purposive random sampling was drawn from an official list of certified organic farmers during Nov. - Dec. 2013. Validity of the questionnaires was assessed by a panel of experts from Department of agriculture, experts from NGO and industry experts in the state. Reliability of the scales of the questionnaire was also computed by Cronbach's Alpha method and the coefficients of Cronbach's Alpha which are appropriate for the study (Gliem and Gliem, 2003). Farmers selected for the survey were smallholders having less than 2 hectare of agricultural land and cultivating fruits (few selected fruits) and vegetables.

\section{Survey design}

The closed ended questionnaire consisted of four groups of questions. The first group referred to sociodemographic profile (Age, gender, education, farm size and years of experience) of the farmers and structural elements of farming. The second group asked about the attitudes towards the adoption of organic $F \& V$ farming. Third group of questions focused on the farmers objectives and the fourth group focused on constraints/barriers that organic smallholder farmer face during production process.

To assess the attitudes of smallholders towards the adoption of organic F\&V a five point Likert scale was used, where $1=$ total disagreement and $5=$ total agreement. The statements selected in this group (Fig. 1), are based on the previous literature in developing countries (Rezvanfar et al., 2011, Chouichom and Yamao, 2010; Sepúlveda et al. 2010; Kafle, 2011; Kings and Ilbery, 2011). Further, to gather information on the importance of a several objectives that farmers wanted to achieve, an ordinal scale ( 1 to 5 was utilized, where $1=$ not at all important and $5=$ very important) was used. The statements considered in this set of questions and their grouping into economic, environmental and socio-cultural objectives (See factor analysis Table Annex 1), were mainly obtained using the 


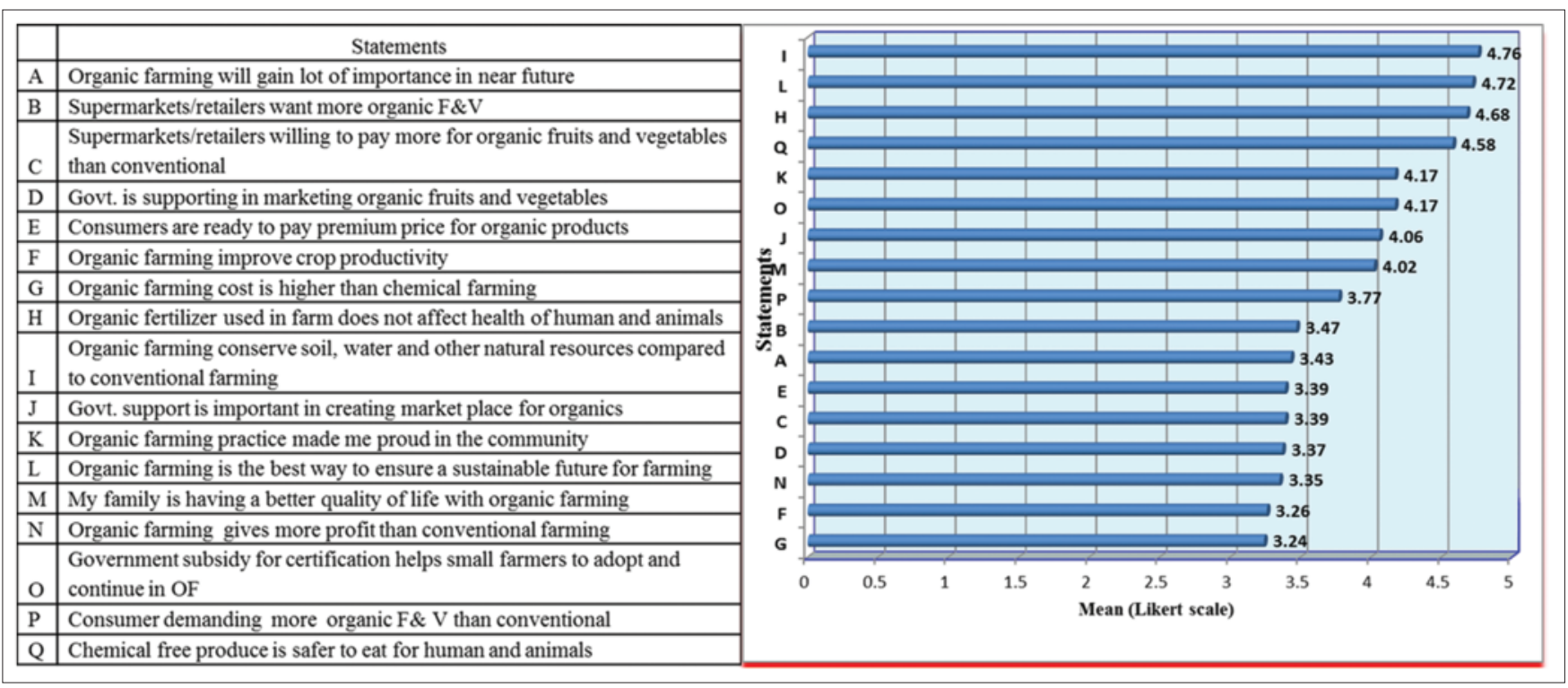

Fig 1. Attitudes of smallholder farmers towards adoption of organic F\&V. (Source: Authors own compilation).

tool for measuring farmers objectives (Willock et al., 1999), and the statements proposed in related studies (Maybery et al., 2009). The attitudes towards adoption of specific farming techniques and farmers objectives are held to determine to a certain degree the behavior of farmers towards the adoption of organic F\&V farming (Maybery, et al., 2005, Willock, et al. 1999), as focused in the present study. The questionnaire prepared was submitted to panel of experts formed by industry experts, university researchers and technicians besides independent research organizations in the state, in order to discuss, decide on the relevance of questions to be included in the questionnaire for the survey.

\section{Design issues in cluster analysis}

Research design issues related to cluster analysis were adequate sample size, detection of outliers, and selection of similarity measures and standardization of the data (Hair, 2009). Addressing these issues is important for increasing the robustness of the analysis. The sample size of 127 was regarded as satisfactory in terms of drawing valid conclusions since a minimum of 100 observations is considered sufficient to perform segmentation using cluster analysis (Hair, 2009). An agglomeration schedule, i.e. an output of cluster analysis, was used to detect outliers and no sample was found having any role in destabilizing outputs. Squared Euclidean distance measures were used as the measures of distance. Standardization of the data was not required since the unit of measurement was equal for all variables.

\section{Statistical analysis}

The factor and cluster statistical analysis were used to analyze the data. Before to this, univariate analysis was performed on all the variables which are considered in the study to observe their individual behavior and to check the presence outliers if any. The factor analysis was used to reduce and summarize information, it was performed on groups of questions referring to smallholder's attitudes towards organic F\&V farming (Likert scale) and on set of questions relating to smallholder's objectives. In these set of questions that included ordinal scale for variables, a factor analysis was used to reduce the variables. From a statistical point of view, in this technique the assumptions of normality and linearity in the variables can be eliminated. At the same time the technique further assists keeping in mind that a minimum of approximately 50 observations is needed for its adequate performance (Hair, 2009). In spite of availability of other data reducing techniques such as Non-linear Principle Component Analysis which is on the basis of qualitative variables - In our study we preferred to use the factor analysis because of its relative ease in the identification of relationships between variables and the components to be retained (Saegusa, et al., 2004). Although, given the differences that exist among attitudes and objectives (Willock et al., 1999), the factor analysis were carried out separately between groups of questions, as conceptually this would be of little validity otherwise.

The Principle Component Analysis (PCA) method was used to extract factors and the KMO and Bartlett's test of sphericity were utilized to measure correlation between variables. Those variables with a lower communality, $b<0.5$ were not considered in the factor analysis since this designates that these variables are not sufficiently correlated with the new factors received. The factors corresponding to those eigenvalues $\geq 1$ were selected in order to gain a better understanding of the factors received - an orthogonal 
rotation was carried out by the Varimax method. The regression method were used to estimate the factor scores and they were consequently saved as new variables to be used as an input in the cluster analysis (Hair, 2009). The factor analysis results in terms of smallholder's objectives are presented in Appendix 1, while the results of factor analysis referring to attitudes are presented in Table 1.

A cluster analysis is a technique whose primary purpose is to group objects (respondents, products, or other entities) based on the characteristics they possess. The resulting clusters should exhibit high internal (withincluster) homogeneity and high external (between-cluster) heterogeneity (Hair, 2009). In the present study, cluster analysis was performed in order to identify smallholder farmers' profiles according to their attitudes towards organic F\&V production. The two-step conglomeration method was adopted. Unlike hierarchical and nonhierarchical methods, a two-step cluster analysis method was adopted in order to seize the highest advantage of the benefits that both methods offer (Hair et al., 1998) and maximum likelihood distance measurement was used, this calculated by using the factors relating to attitudes which are obtained after factor analysis (Table 1) and the number of conglomerates was automatically determined. Having identified the clusters, they were then characterized on the basis of their orientation towards organic $F \& V$ production, factors relating to attitudes and objectives of the farmers (Table 2). In order to determine the most important variables that allow discrimination between clusters, the contingency tables were utilized with their Kruskal-Wallis test to compare ranges of independent samples (Glantz and Ruiz, 2006). The Statistical Package for Social Sciences (SPSS 16.0) was selected for analyzing the data (Blaikie, 2003).

\section{RESULTS AND DISCUSSION}

\section{Socio-demographic profile}

Both industry and academic studies have investigated the socio-demographic profiles of the organic farmers across the world, and to date, these studies have yielded conflicting results. In this study, the socio-demographic profiles of the smallholder organic farmers were analyzed, and results revealed that, majority of the respondents were male $(94 \%)$ while only $6 \%$ were female (Table 3 ). Their ages ranged between 23-78 years, with an average of 41.64 years. According to (Singh and George, 2012) the average age of the conventional farmers in India was 43 years, which shows that the organic growers are younger than conventional. Conversely, as reported by (Bourn

Table 1: Factor analysis of attitudes of smallholder Farmers towards Adoption of Organic Fruits and Vegetables Cultivation

\begin{tabular}{|c|c|c|c|c|c|c|}
\hline \multirow[t]{2}{*}{ Variables (Likert scale*) } & \multicolumn{6}{|c|}{ Factor loadings } \\
\hline & Mean & $\begin{array}{l}\text { Market } \\
\text { factor }\end{array}$ & $\begin{array}{c}\text { Environment } \\
\text { factor }\end{array}$ & $\begin{array}{l}\text { Support } \\
\text { factor }\end{array}$ & $\begin{array}{l}\text { Benefit and } \\
\text { cost factor }\end{array}$ & $\begin{array}{l}\text { Community } \\
\text { factor }\end{array}$ \\
\hline Organic farming will gain lot of importance in near future & 3.43 & 0.967 & & & & \\
\hline Supermarkets/retailers want more organic F\&V & 3.47 & 0.920 & & & & \\
\hline $\begin{array}{l}\text { Supermarkets/retailers willing to pay more for organic fruits and } \\
\text { vegetables than conventional }\end{array}$ & 3.39 & 0.908 & & & & \\
\hline Govt. is supporting in marketing organic fruits and vegetables & 3.37 & 0.856 & & & & \\
\hline Consumer demanding more organic $F \& V$ than conventional & 3.77 & 0.772 & & & & \\
\hline Consumers are ready to pay premium price for organic products & 3.39 & 0.666 & & & & \\
\hline $\begin{array}{l}\text { Organic farming conserve soil, water and other natural resources } \\
\text { compared to conventional farming }\end{array}$ & 4.76 & & 0.917 & & & \\
\hline Organic farming is the best way to ensure a sustainable future for farming & 4.72 & & 0.841 & & & \\
\hline Organic fertilizer used in farm does not affect health of human and animals & 4.68 & & 0.710 & & & \\
\hline Chemical free produce is safer to eat for human and animals & 4.58 & & 0.610 & & & \\
\hline $\begin{array}{l}\text { Government subsidy for certification helps small farmers to adopt and } \\
\text { continue in OF }\end{array}$ & 4.17 & & & 0.911 & & \\
\hline Govt. support is important in creating market place for organics & 4.06 & & & 0.891 & & \\
\hline Organic farming Improve crop productivity & 3.26 & & & & 0.796 & \\
\hline Organic farming gives more profit than conventional farming & 3.35 & & & & 0.719 & \\
\hline Organic farming cost is higher than chemical farming & 3.24 & & & & & \\
\hline My family is having a better quality of life with organic farming & 4.02 & & & & & 0.775 \\
\hline Organic farming practice made me proud in the community & 4.17 & & & & & 0.549 \\
\hline Eigen value & & 4.57 & 2.64 & 1.83 & 1.43 & 1.41 \\
\hline Variance \% & & 26.90 & 15.58 & 10.79 & 8.46 & 8.32 \\
\hline Total Variance \% & & 26.90 & 42.49 & 53.27 & 61.73 & 70.05 \\
\hline Cronbachs Alpha & & 0.769 & 0.795 & 0.793 & 0.616 & 0.610 \\
\hline
\end{tabular}

Extraction method: Principal component analysis. Rotation method: Varimax with Kaiser normalization. Strongly disagree-1; strongly agree-5, Bartlett's test of sphericity $(\mathrm{p}=0.001)$ and the $\mathrm{KMO}=0.73$ 
Table 2: Characterization of the clusters obtained based on the factor scores

\begin{tabular}{|c|c|c|c|}
\hline Variables & $\begin{array}{c}\text { Cluster } 1 \\
\mathrm{n}=57\end{array}$ & $\begin{array}{c}\text { Cluster } 2 \\
\mathrm{n}=30\end{array}$ & $\begin{array}{c}\text { Cluster } 3 \\
n=40\end{array}$ \\
\hline \multicolumn{4}{|l|}{$\begin{array}{l}\text { Smallholder farmers Attitude } \\
\text { towards organic fruits \& } \\
\text { Vegetables Production }\end{array}$} \\
\hline Market factor ${ }^{*}$ & -0.83 & 0.23 & 0.33 \\
\hline Environmental factor ${ }^{*}$ & -0.41 & -0.32 & 0.65 \\
\hline Support factor ${ }^{* * * *}$ & -0.09 & 0.14 & 0.03 \\
\hline Benefit cost factor & 0.07 & -0.03 & -0.09 \\
\hline Community factor & 0.12 & -0.30 & 0.05 \\
\hline \multicolumn{4}{|l|}{$\begin{array}{l}\text { Objectives of the smallholder } \\
\text { farmers }\end{array}$} \\
\hline Economic objective factor ${ }^{* * * *}$ & 0.12 & -0.01 & -0.16 \\
\hline Environment objective factor ${ }^{*}$ & -0.85 & 0.26 & 0.50 \\
\hline $\begin{array}{l}\text { Socio-cultural objective } \\
\text { factor* }\end{array}$ & 0.44 & -0.48 & 0.65 \\
\hline
\end{tabular}

Table 3: Socio-demographic characteristics of the smallholder

\begin{tabular}{|c|c|c|c|}
\hline Variable & Frequency & & 6 \\
\hline \multicolumn{4}{|l|}{ Gender } \\
\hline Male & 119 & \multicolumn{2}{|c|}{94.0} \\
\hline Female & 08 & \multicolumn{2}{|c|}{6.0} \\
\hline \multicolumn{4}{|l|}{ Age (23-78 years) } \\
\hline $18-30$ & 18 & \multicolumn{2}{|c|}{14.0} \\
\hline $31-40$ & 40 & \multicolumn{2}{|c|}{32} \\
\hline $41-50$ & 50 & \multicolumn{2}{|c|}{39} \\
\hline $51-60$ & 16 & \multicolumn{2}{|c|}{13} \\
\hline$>61$ & 03 & \multicolumn{2}{|c|}{02} \\
\hline Mean (age) & 41.64 & & \\
\hline \multicolumn{4}{|l|}{ Education } \\
\hline Illiterate & 23 & \multicolumn{2}{|c|}{18} \\
\hline Primary & 36 & \multicolumn{2}{|c|}{28} \\
\hline Secondary & 63 & \multicolumn{2}{|c|}{50} \\
\hline \multirow[t]{2}{*}{ Higher (University Education) } & 05 & \multicolumn{2}{|c|}{04} \\
\hline & Min & Max & Mean \\
\hline Experience (years) & 1 & 15 & 3.9 \\
\hline Organic farm size (acres) & 0.50 & 5 & 1.8 \\
\hline
\end{tabular}

High school education: Elementary school+3 years; Bachelors education: High school $+3-4$ years and Master and above: Bachelors $+2-5$ years

and Prescott, 2002; Rezvanfar er al., 2011) average age of conventional farmers in Iran and Thailand were 39.5 and 43.74 years respectively, as against 40 and 48.6 years respectively in the same study for organic farmers, which means that, the organic farmers are older than the counterpart. Further, a high percentage of farmers (50\%) have completed the secondary education $(10+2$ years) and $28 \%$ of them were having primary education ( 7 years), $4 \%$ of them have university education (15 years) and 18 per cent of the farmers were illiterate having no formal education. These results are in line with other studies which state relatively high levels of literacy and education of organic farmers mainly when compared to conventional farmers (Duram, 1999, Iliopoulou et al., 2011; Chouichom and Yamao, 2010). The average area of exploited land by organic fruits and vegetables smallholder's farmers were 1.8 acres which is significantly smaller compared with national average 3.55 acres (1.42ha) for small farmers and 1 acre (0.39ha) for marginal farmers (Agriculture 2010-11). These results contrast with the reviews of comparative data on organic farming. The latter highlighted that, the average farm holding size of organic farms were larger than conventional ones (Offermann and Nieberg, 2000; Chouichom and Yamao, 2010). Furthermore, the mean organic F\&V production experience that interviewed producers have 3.9 years although there were producers with less experience (1 year) or more experience (15 years) producing organically.

\section{Attitudes of smallholder farmers towards organic fruits and vegetables production}

The results from our study indicate that smallholder organic farmers express diverse attitudes towards adoption of organic F\&V farming (Fig. 1) in Karnataka, India. They were asked to assess the importance of 17 statements providing, so, inputs for the analysis of attitudes for adoption in the five points Likert scale. Farmers in general consider that producing organically, to a great extent, conserves natural resources, that organic fertilizers used during production are safe and do not affect human nor animal health, finally that it consists of the best way towards sustainable farming. Furthermore, growing organically make them feel proud of their work. Besides that, they believe that the role of government is very important in promoting organic farming by providing subsidy for certification and also in creating the proper conditions for markets for their organic produce. However, farmers tend to agree less with the statements that organic farming costs were higher than on chemical farming. On the contrary, it was held that it improves crop productivity and it gives more profit than conventional farming. In addition, they don't completely agree with statements asserting that government support for marketing organic $F \& V$, the will of retailers and consumers to pay premium prices and organic $\mathrm{F} \& \mathrm{~V}$ farming in the country will gain more importance in the near future. These results were in line with studies in developing countries which state that reasons for adopting organic farming were mainly economic, environmental, connected to government support and marketing concerns (Khaledi et al., 2007, Strochlic and Sierra, 2007).

After carrying out a factor analysis on these scales, five factors emerged which explain $70.05 \%$ of the total variance (Table 1). Bartlett's test of sphericity $(p=0.001)$ and the $K M O=0.73$, indicate that the variables comprised in the analysis are significantly correlated to each other. The first 
factor ingeminate six variables related to the marketing of organic F\&V, explaining $26.90 \%$ of the total variance after varimax rotation - it is termed as "marketing factor". As presented in Table 1, this factor includes statements that examine the farmer's opinions about the marketing of organic $F \& V$, government's role in creating market facilities for the farmers and consumers/retailers willingness to pay premium price for acquiring organic products. As explained in the literature (McEachern and Willock, 2004), "market forces" were particularly important to farmers indicating strong farmer's optimism about the future of organic farming irrespective of their farm size and type. Results clearly indicate that, market factors were of very much importance for smallholder farmers' adoption of organic $\mathrm{F} \& \mathrm{~V}$ production. This is all the more evident as these producers were having lesser land holding (average 1.8 acre) which remains the source for their livelihood and hence they look for higher economic benefits rather any other advantages as first criteria.

"Environment factor" corresponded to the designation associated to the second factor comprehending four variables which explain $15.58 \%$ of the total variance; it described farmer's concern about animal's welfare, environmental pollution, natural resources and sustainability. After mean score analysis interesting aspects emerged, namely: all the statements in factor two received mean score more than four indicating agreement to strongly agreement. However, as income alone was not a predictor of environmental concern, it was also necessary to have positive attitude towards the environment (Lynne and Rola, 1988). Subsequently, this result has been challenged by several studies, which suggest that profit motives were stronger than environmental (Carr and Tait, 1991, McEachern and Willock, 2004). Therefore, it cannot be concluded without further wider study, that a positive environmental attitude was sufficient to predict organic conversion. Further studies (Padel, 2001; Fairweather, 1999) reported that, environmental aspects seem not to be dominant motives in farmers decision to grow organically, since it is characterized as of moderate importance. Accordingly, only $13 \%$ of respondents state that environmental reasons were of high importance in stimulating behavior, while for another $13 \%$ of them environment has no importance at all. However, farmers with broader environmental concerns and a positive attitude to challenge and change customary ways of production have been identified as more likely to consider organic farming as a potential alternative (Duram, 2000). Similarly, environmental concerns have been identified (Ashmole, 1994) as the most important factor for organic farmers.

The third factor explained $10.79 \%$ of the original variance and the statements registered under this factor were designated by the term "Support factor". These statements specifically reflect opinions about government's role in the support of smallholder farmers in the form of subsidies during initial years of productive conversion. Subsidies may be understood more specifically here in terms of the provision of sponsorship for certification during productive conversion and the creation of market platforms for organic produce in the local level. These results, in agreement with correlate studies (Fairweather, 1999), revealed that institutional support was one of the important motivating factors for the adoption of organic farming amidst small farmers. The fourth factor includes statements related to crop productivity and profitability of organic F\&V farming compared to conventional and it is termed "Benefit \& Cost factor". Farmers here expressed the belief that organic farming will give more yield per unit area and in turn they can earn more profit from organic practice. This fourth factor comprehends two statements and explains $8.46 \%$ of the total variance. The results here also find support in the literature on these topics (Carr and Tait, 1991). Finally the last factor, named as "Community factor", contained two statements and explains $8.32 \%$ of the total variance. These statements express organic farming's relevance in their community as farmers feel proud and clear improvements in their life quality by practicing organic farming.

\section{Farmer's Groups}

In more detailed analysis, it is observed that there were groups of farmers with diversified attitudes to the subjects investigated. This may be approached through varying degrees of orientation towards organic F\&V production. Three groups of smallholder farmers were identified. Based on the previously described factors, a cluster analysis was created to verify the existence of homogeneous groups of farmers with different propensities towards different factors (Sepúlveda et al., 2010; Annunziata and Vecchio, 2011). The two-step cluster analysis was carried out on factor scores using as a distance variables and KruskalWallis test was made to compare two independent sample ranges. The factor scores of smallholder farmers with regard to the five factors related to attitudes, suggests that there were three groups of farmers. The groups were categorized and characterized based on the factors obtained from attitudes and farmers objectives towards adoption of organic F \& V farming and the results are demonstrated in Table 2. The attitudinal variables such as, market factor $(p<0.001)$, Environmental factor $(p<0.001)$, Government support factor $(p<0.05)$ and objectives factors such as, Economic objective factor $(\phi<0.05)$, environmental objective factor $(p<0.001)$ and Socio-cultural objective factor $(p<0.01)$, enables us to differentiate between the three clusters obtained. We can notice that significative differences were 
found between group's ratings and the six factors. These three groups were of a substantial and comparable size.

Cluster one was constituted of 57 respondents (44.80\% of the sample) and it was the largest group having highest negative scores. They showed negative attitudes towards market, environment and support factors and hence this group was termed as 'Pessimistic farmers of organic F\&V". This negative attitude may be due to the fact that the lack of sufficient market facilities to sell organic F\&V leading to uncertain demand from buyers compels them to sell their produce in conventional markets without price premiums. However, on the other hand they have quite a positive attitude towards factors such as Benefit cost and community factors, considering that organic farming gives more productivity and yields higher returns. In relation to objectives, the attitude towards economic and socio cultural objectives were fairly positive, indicating that it improves life quality in the community while providing farmers with a sense of pride. The propensities of individual groups towards respective factors are as shown in the Fig. 2. Cluster two, which was smaller in size, was constituted of 30 respondents $(23.60 \%$ of the sample). Here there was not as much certainty that organic $F \& V$ production renders economic and environmental benefits, i.e. their attitude was fairly negative towards environmental, benefit cost and community factors. In relation to their objectives, they have negative attitude towards economic and socio-cultural factors. Thus, farmers in this cluster have relatively weaker disposition to convert to organic production, hence the group label "Farmers with little orientation towards organic F\& $V$ production". Cluster three was comprised of 40 respondents $(31.50 \%)$ and displays general positive orientation towards the majority of the factors, thus it was termed "Optimistic farmers of organic F\& $V$ ”. There was high level of agreement towards market and environmental factors and slight positive agreement towards Support, Benefit Cost and Community factors. Accordingly, in this cluster farmers disclose stronger optimism in relation to economic, environmental and other benefits that is to a greater profitability in the production of organic $\mathrm{F} \& \mathrm{~V}$ in the region. Gil Roig and colleagues (Gil Roig et al., 2003) highlighted that the most optimist farmers in the organic sector were those that opted for organic fresh produce production. Further, the younger farmers were those that appear to be more willing to adopt organic farming in comparison to older generation, they were more willing to take risks in adopting new forms of production techniques (Hansson, 2008; Kafle, 2011). In addition, younger farmers were more open to new ideas and technologies which may help them to take decisions that increase their production efficiency and from which greater economic returns may derive (Hansson, 2008).

On the contrary to optimists, pessimists were not as convinced that organic $F \& V$ production was important in terms of environment and market opportunity benefits, but they boast economic and socio-cultural objectives for adoption along with community and benefit cost motivations. At this point it is worth to call attention to the configuration of motivations and drivers in this cluster in order to consider possible avenues for producing shifts in this segment and hence promoting higher level of conversion to organic farming. In this sense, as seen, farmers in this segment don't exhibit the same levels of certainty in regard to organic farming production methods as environmentally friendly, rendering clear economic

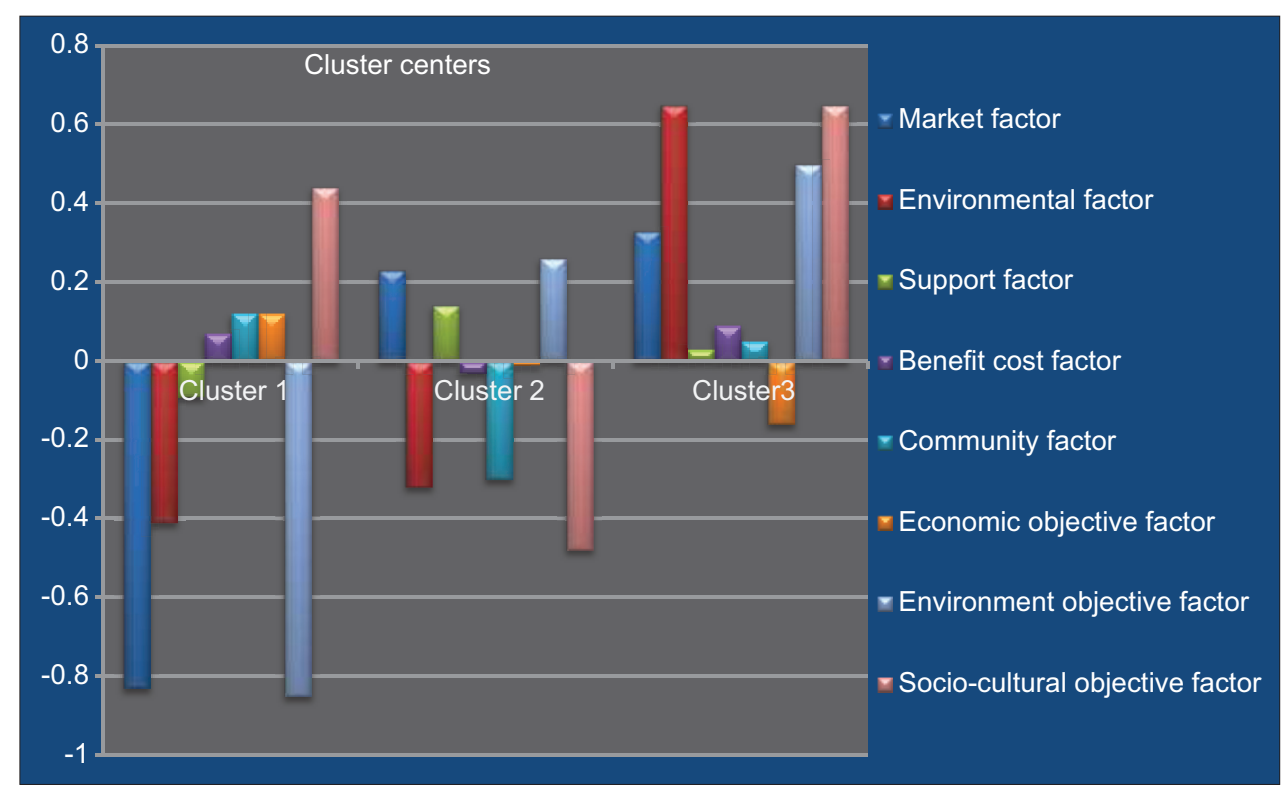

Fig. 2. Cluster centers based on the factor scores. (Source: Authors own compilation). 
benefits nor of any socio-cultural advantage in their life on the community level. At the same time, this segment lies between optimists and pessimists with reference to their orientation towards various factors.

\section{Barriers of smallholder farmers towards production of organic F\&V}

It was essential to identify potential barriers to the development of organic fruits and vegetables farming from the perspective of smallholder farmers. For this purpose, 16 organic $\mathrm{F} \& \mathrm{~V}$ production related barriers statements were formulated based on the aspects found in previous organic farming related studies (Khaledi et al., 2007; Veisi et al., 2013; Strochlic and Sierra, 2007; Niemeyer and Lombard, 2003) and the same were validated with experts in the study region. For each statement, respondents mentioned their level of agreement on a five-point scale in which $1=$ strongly disagree and 5= strongly agree. The variables to submit to factorial reduction were chosen on the basis of the analysis of the correlations existing among the original variables (Verified with Bartlett's test for sphercity $p=0.001$ and the $\mathrm{KMO}=0.74)$, it indicates that the variables comprised in the analysis were significantly correlated to each other. The factors were chosen on the basis of the eigenvalue $(\geq 1)$ criterion, as well as consideration of the cumulative variance explained by the factors taken together. Principle component analysis with the varimax rotation method (Kaiser, 1958) revealed the existence of four factors, which all together explain 68.52 per cent of the total variance. Table 4 presents the rotated component matrix, by using the factor loadings; the variables were grouped into their respective factors and were renamed according to their collective representation.

All of the variables loading highly on factor one were related to production of organic F\&V and regarding their collective representation they can be termed as "Production Barriers". The first factor comprised six variables related to the production problems which were faced by the smallholder farmers and it explains 24.12 per cent of the total variance after varimax rotation (Table 4). Production barriers include: lack of skills to the farmers to grow and manage their farm organically, poor production due to inability to manage weeds and pests using organic methods, lack of access to organic inputs, insufficient cattle population to prepare manure onsite and low yields associated during initial years of adoption. These results are in line with views expressed in the case of Iran (Veisi et al., 2013).

"Marketing Barriers" corresponded to the designation associated to the second factor comprehending five variables which explain 17.90 per cent of the variance. The factor describes barriers which were associated with marketing of organically grown $\mathrm{F} \& \mathrm{~V}$ in the domestic market and with the capacity to claim premium prices for organics. Walz (1999) identified that the most severe barriers to organic transition were lack of experience in organic production and information, and an inability to identify markets (Walz, 1999). In addition, an Italian study states that the diffusion of organic farming was found initially to be hindered by the lack of extension, information and market awareness by farmers (SIMOCA, 2004). The ability to obtain stable and lucrative markets for organic $F \& V$ are the main challenge cited by farmers and was one of the main barriers to the more widespread adoption of organic agriculture in the study region.

The third factor constituted three variables and explains 15.50 per cent of the total variance. It was associated with the technical and managerial barriers to adopt and produce fruits and vegetables organically. Thus this factor was named as "Technical-Managerial Barriers". In a number of studies, technical factors and lack management skills were identified that deter organic farmers from going ahead with organic farming (Schneeberger et al., 2002; De Buck et al., 2001).

The last factor was comprised of two variables; explained 11 per cent of the original variance and the statements loading on this factor were designated by the term "Economic $\&$ Financial Barriers". These statements specifically reflect concerns towards financial loss associated with low yield during initial years of organic cultivation and also high certification costs. This was in agreement with results by (Veisi et al., 2013). After mean score analysis interesting aspects emerged, namely: all the statements in factors two, three and four received mean scores more than four indicating agreement to strongly agreement towards statements expressing the relevance of barriers on the order of severity associated to produce fruits and vegetables organically in the study area. A group of authors (Sterrett et al., 2005) reported about the conversion to organic production on 142 Virginia farms. They identified various barriers to organic fresh produce production, with the primary barrier being the cost and uncertainty of the certification process. Other barriers included lack of marketing information and cost/budget information, availability and cost of labor, production problems, and lack of production information.

\section{CONCLUSIONS}

The present research focused on analyzing the attitudes of smallholder farmers towards the production of organic $F \& V$ and identifies groups of smallholder farmers in accordance with their attitudes and their relationship with 
Table 4: Factor analysis of barriers of smallholder farmers towards production of organic fruits and vegetables

\begin{tabular}{|c|c|c|c|c|c|}
\hline \multirow[t]{2}{*}{ Variables (Likert scale*) } & \multicolumn{5}{|c|}{ Factor loadings } \\
\hline & Mean & $\begin{array}{l}\text { Production } \\
\text { barriers }\end{array}$ & $\begin{array}{l}\text { Marketing } \\
\text { barriers }\end{array}$ & $\begin{array}{l}\text { Technical- } \\
\text { managerial }\end{array}$ & $\begin{array}{l}\text { Economic } \\
\text { and financial }\end{array}$ \\
\hline Lack of skills to produce organically & 3.39 & 0.927 & & & \\
\hline Poor production due to inability to address weeds and pests using organic methods & 3.47 & 0.887 & & & \\
\hline $\begin{array}{l}\text { Lack of access to inputs to produce organically such bio fertilizers, bio-pesticides, } \\
\text { seeds, animal feed etc }\end{array}$ & 3.37 & 0.832 & & & \\
\hline Insufficient cattle population to prepare compost/manure & 3.39 & 0.716 & & & \\
\hline Low yields associated during initial years & 3.77 & 0.683 & & & \\
\hline High incidence of pest and diseases & 3.57 & 0.627 & & & \\
\hline Lack of developed marketing and distribution channels for organic farmers & 4.76 & & 0.914 & & \\
\hline Difficulties obtaining organic price premiums and securing stable markets & 4.72 & & 0.851 & & \\
\hline Buyer won't take all the produce produced organically from producer & 4.63 & & 0.645 & & \\
\hline Lack of access to information on prices and markets for organic products & 4.58 & & 0.642 & & \\
\hline Lack of government support to market organic produce in separate market place & 4.68 & & 0.639 & & \\
\hline Low coverage of organic agriculture extension programs & 4.06 & & & 0.948 & \\
\hline Lack of skills to manage farm organically & 4.15 & & & 0.903 & \\
\hline Limited access to technical assistance & & & & 0.861 & \\
\hline Low income & 4.04 & & & & 0.856 \\
\hline Certification costs which can be particularly onerous for smaller farmers & 4.02 & & & & 0.830 \\
\hline Eigen value & - & 4.44 & 2.69 & 2.43 & 1.42 \\
\hline Variance \% & - & 24.12 & 17.90 & 15.50 & 11.00 \\
\hline Total Variance \% & - & 24.12 & 42.02 & 57.52 & 68.52 \\
\hline Cronbachs Alpha & - & 0.714 & 0.756 & 0.700 & 0.678 \\
\hline
\end{tabular}

Extraction Method: Principal Component Analysis. Rotation Method: Varimax with Kaiser Normalization. ${ }^{*} 1=$ Strongly disagree, $5=$ Strongly agree. KMO=0.74

farming objectives and the degree of orientation of farmers towards organic $\mathrm{F} \& \mathrm{~V}$ production and, to investigate the main barriers for the development of organic farming by smallholder farmers in the study region.

After observing an array of diverse attitudes towards adoption of organic F\&V farming a number of relevant factors were identified, namely market forces and environmental concerns which were most valued by smallholder farmers followed by government support factor, benefit cost and community factor for organic F\&V production. In this sense, it may be asserted that among the driving factors to conversion was information about increasing demand for organic F\&V and better access to markets. Government initial support for these farmers by means of subsidies for certification and announcing price premiums may help bringing more and more area under organic farming, which indicates the crucial character of such planned interventions for the promotion of conversion. Another noteworthy fact is that environmental concern is most valued as an objective of their farming as compared to conventional productive modes, which points out its potential as a driving force behind the increase in organic farming adoption among these stakeholders.

Additionally, three groups of smallholder farmers were determined and clearly characterized by their different attitudes, objectives and production orientations. Optimists (cluster 3) are second largest group having highest positive orientation towards majority of the factors followed by cluster 2. Consequently, the organic regulatory bodies, government agencies and firms who are involved in organic $\mathrm{F} \& \mathrm{~V}$ trade should consider these groups of producers as target groups with the aim of future policies and calibrating strategies to encourage a greater adoption of organic F\&V farming in Karnataka state, India.

Finally, based on the empirical results, production barriers are the most mentioned challenges by smallholders followed by marketing, techno-managerial and economic and financial. Hence, agriculture development policy makers should consider these barriers to overcome by taking necessary actions in the direction of promoting smallholders in organic farming. These recommendations may be still further complemented by a comprehensive effort to educate consumers of the benefit of organics not just in the immediate factors of awareness as environment and health benefits but also in its connection to the support of local communities of organic smallholder producers. Such steps may serve decisive strengthening processes boosting further growth in an organic sector still in its early phase of development.

\section{Future research}

Since the sample in this study is non-representative, that is, only comprised of smallholder farmers growing few types of fruits and vegetables based in south Karnataka, the generalization of the findings should be approached 
with caution. Given the importance of this issue and the scarce literature available in the country, the same research should be carried out with smallholders growing other types of fruits and vegetables from other parts of the country with a wider variety and dimension of samples in order to verify and produce more generalizable results.

\section{ACKNOWLEDGMENTS}

We wish to thank all the organic producers and retailers who patiently shared their time, insights and views about the organic farming. Special thanks are to Dr. Lalit Achoth, Professor and Head, Department of Dairy Economics KVAFS University, Hebbal campus, Bangalore, Dr. M. G. Chandrakant Professor Department of Agricultural Economics University of Agricultural Sciences, GKVK, Bangalore and Dr. Krishnamurthy Professor and Head, Department of Agriculture extension, GKVK, Bangalore for providing critical comments and inputs on paper. Finally, we extend our special thanks to our collogues in the department of agricultural economics, Humboldt university of Berlin, Germany for providing us important inputs during data analysis and writing the research article.

\section{Abbreviations}

$\mathrm{F} \& \mathrm{~V}=$ Fruits and Vegetables

$\mathrm{FAO}=$ Food and Agriculture Organization

IFAD $=$ International Fund for Agricultural Development

$\mathrm{KMO}=$ Kaise-Mayer-Olkin Index

$\mathrm{OF} \quad=$ Organic Farming

\section{Author contribution}

R.N.: Main researcher, collected data, analyzed the data and wrote article. N.V.G.: Supported in providing literature, data collection, and analysis. W.B.: Research supervisor. Finally, G.D.: Proofreading and corrected the article.

\section{REFERENCES}

Agriculture, Census. 2010-11. All India Report on Number and Area of Operational Holdings."28-46. Available from: http://www. agcensus.nic.in/document/agcensus2010/completereport.pdf 12.05.2014

Annunziata, A. and R. Vecchio. 2011. Factors Affecting italian consumer attitudes toward functional foods. AgBioForum, 14(1): 20-32.

APEDA. 2014. National Programme for Organic Production. Available from: http://www.apeda.gov.in/apedawebsite/organic/Organic_ Products.htm [Last accessed on 2014 May 07].

Ashmole, A. 1994. The organic values of Agri-Culture. University of Edinburgh.

Blaikie, N. 2003. Analyzing Quantitative Data: From Description to Explanation. Sage, London.

Bolwig, S., P. Gibbon and S. Jones. 2009. The economics of smallholder organic contract farming in tropical Africa. World Dev. 37(6): 1094-1104.

Bourn, D. and J. Prescott. 2002. A comparison of the nutritional value, sensory qualities, and food safety of organically and conventionally produced foods. Crit. Rev. Food Sci. Nutr. 42(1): 1-34.

Carr, S. and J. Tait. 1991. Differences in the attitudes of farmers and conservationists and their implications. J. Environ. Manage. 32(3): 281-294.

Chouichom, S. and M. Yamao. 2010. Comparing opinions and attitudes of organic and non-organic farmers towards organic rice farming system in north-eastern Thailand. J. Organ. Syst. 5(1): 25-35.

De Buck, A. J., I. Van Rijn, N. G. Roling and G. A. A. Wossink. 2001. Farmers' reasons for changing or not changing to more sustainable practices: An exploratory study of arable farming in the Netherlands. J. Agric. Educ. Ext. 7(3): 153-166.

Mahendra Dev, S. 2012. Small farmers in India: Challenges and opportunities. Indira Gandhi Institute of Development Research, Mumbai.

Duram, L. A. 1999. Factors in organic farmers' decisionmaking: diversity, challenge, and obstacles. Am. J. Altern. Agric. 14: 2-10.

Duram, L. A. 2000. Agents' perceptions of structure: How Illinois organic farmers view political, economic, social, and ecological factors. Agric. Hum. Values. 17(1): 35-48.

Egelyng, H. 2009. Organic agriculture: Glocalisation options for the South? Organic Farming-Perspectives and Experiences. ICFAI University Press, Bangalore. p. 186-201.

Fairweather, J. R. 1999. Understanding how farmers choose between organic and conventional production: Results from New Zealand and policy implications. Agric. Hum. Values 16(1): 51-63.

Roig, G., J. María, A. Perdiguero and M. Ben-Kaabia. 2003. Factores determinantes de las expectativas de futuro de los ganaderos aragoneses de ovino.

Glantz, S. A. and A. M. P. Ruiz. 2006. Bioestadística: McGraw Hill, México.

Gliem, J. A. and R. R Gliem. 2003. Calculating, interpreting, and reporting Cronbach's alpha reliability coefficient for Likert-type scales.

Hair, J. F. 2009. Multivariate Data Analysis. $7^{\text {th }}$ ed. Prentice Hall, Upper Saddle River.

Hair, J. F., R. E. Anderson, R. L. Tatham and W. C. Black. 1998. Multivariate analysis. Prentice Hall International, Englewood.

Hansson, H. 2008. How can farmer managerial capacity contribute to improved farm performance? A study of dairy farms in Sweden. Acta Agric. Scand Section C5(1): 44-61.

Iliopoulou, D., K. Douma and C. Giourga. 2011. Motives and barriers to development of organic olive production." Book of Abstract. International Conference on Organic Agriculture and Agro-Eco Tourism in the Mediterranean.

Kafle, B. 2011. Factors affecting adoption of organic vegetable farming in Chitwan District, Nepal. World J. Agric. Sci. 7(5): 604-606.

Kaiser, H. F. 1958. The varimax criterion for analytic rotation in factor analysis. Psychometrika. 23(3): 187-200.

Kallas, Z., T. Serra and J. M. Gil. 2009. Farmer's objectives as determinant factors of organic farming adoption. 113th EAAE Seminar, Chania, Crete, Greece, September.

Khaledi, M., R. Gray, S. Weseen and E. Sawyer. 2007. Assessing the Barriers to Conversion to Organic Farming: An Institutional Analysis. Department of Agricultural Economics, University of Saskatchewan.

Kilcher, L. 2007. How organic agriculture contributes to sustainable development. J. Agric. Res. Trop. Subtrop. Suppl. 89: 31-49.

Kings, D. and B. Ilbery. 2011. Farmers' Attitudes Towards Organic and Conventional Agriculture: A Behavioural Perspective. Organic Food and Agriculture: New Trends and Developments in the 
Social Sciences. InTech, Open Access Publishers. p. 145-168.

Lynne, G. D. and L. R. Rola. 1988. Improving attitude-behavior prediction models with economic variables: Farmer actions toward soil conservation. J. Soc. Psychol. 128(1): 19-28.

Maybery, D., L. Crase and C. Gullifer. 2005. Categorising farming values as economic, conservation and lifestyle. J. Econ. Psychol. 26(1): 59-72.

McEachern, M. G. and J. Willock. 2004. Producers and consumers of organic meat: A focus on attitudes and motivations. Br. Food J. 106(7): 534-552.

Niemeyer, K. and J. Lombard. 2003. Identifying problems and potential of the conversion to organic farming in South Africa. Meeting of the Agricultural Economic Association of South Africa (AEASA), Pretoria, South Africa.

Nordlund, E. and H. Egelyng. 2008. Perceived Constraints and Opportunities for Brazilian Smallholders Going Organic: A case of coffee in the state of Minas Gerais. Cultivating Future Based Sci. 2: 462-465.

Offermann, F. and H. Nieberg. 2000. Economic performance of organic farms in Europe: Universität Hohenheim, Institut für Landwirtschaftliche Betriebslehre.

Padel, S. 2001. Conversion to organic farming: A typical example of the diffusion of an innovation? Sociol. Rural. 41(1): 40-61.

Reardon, T. and J. A. Berdegue. 2002. The rapid rise of supermarkets in Latin America: Challenges and opportunities for development. Dev. Policy Rev. 20(4): 371-388.

Rezvanfar, A. G. Eraktan E. Olhan. 2011. Determine of factors associated with the adoption of organic agriculture among small farmers in Iran. Afr. J. Agric. Res. 6(13): 2950-2956.

Saegusa, R. H. Sakano S. Hashimoto. 2004. Nonlinear principal component analysis to preserve the order of principal components. Neurocomputing, 61: 57-70.

Schneeberger, W. I. Darnhofer and M. Eder. 2002. Barriers to the adoption of organic farming by cash-crop producers in Austria. Am. J. Alternat. Agric. 17(1): 24-31.

Scialabba, N. 2007. Organic Agriculture and Food Security. International Conference on Organic Agriculture and Food Security.

Sepúlveda, W. S., M. T. Maza, L. Pardos, E. Fantova and Á. R Mantecón. 2010. Farmers' attitudes towards lamb meat production under a protected geographical indication. Small Rumin. Res. 94(1): 90-97.

Shah, T., S. Verma, V. Bhamoriya, S. Ghosh and R. Sakthivadivel. 2005. Social impact of technical innovations: Study of organic cotton and low cost drip irrigation in the agrarian economy of West Nirmar Region.

SIMOCA, Project. 2004. Development of best-practices models at farm and catchments level for multifunctional and organic agriculture in the Italian case study area. WP2 Italian Report.

Singh, S. and R. George. 2012. Awareness and beliefs of farmers in Uttarakhand, India. J. Hum. Ecol. 37(2): 139-149.

Sirieix, L., P. R. Kledal and T. Sulitang. 2011. Organic food consumers' trade-offs between local or imported, conventional or organic products: A qualitative study in Shanghai. Int. J. Consum. Stud. 35(6): 670-678.

Sterrett, S., G. E. Groover, D. B. Taylor and K. Mundy. 2005. Describing Organic Agricultural Production in Virginia Results of the 2004 Farm Survey Virginian's Rural Economic Analysis Program. Department of Agricultural and Applied Economics, College of Agriculture and Life Sciences, Virginia Tech.

Strochlic, R. and L. Sierra. 2007. Conventional, Mixed and Deregistered Organic Farmers: Entry Barriers and Reasons for Exiting Organic Production in California. California Institute for Rural Studies, Davis, CA. Available from: http://www.cirsinc.org/ docs/organic_transitions.pdf.

Veisi, A., M. Gholami N. Shiri. 2013. What are the barriers to the development of organic farming? Sci. Papers: Manag. Econ. Eng. Agric. Rural Dev. 13(3).

Walz, E. 1999. Final results of the Third National Organic Farmer's Survey. Organic Farming Research Foundation:126.

Willer, H., J. Lernoud and L. Kilcher. 2013. The World of Organic Agriculture: Statistics and Emerging Trends 2013. Research Institute of Organic Agriculture (FiBL) \& Bonn: International Federation of Organic Agriculture Movements (IFOAM), Frick, Switzerland.

Willock, J., I. J. Deary, M. M. McGregor, A. Sutherland, G. EdwardsJones, O. Morgan, B. Dent, R. Grieve, G. Gibson and E. Austin. 1999. Farmers' attitudes, objectives, behaviors, and personality traits: The Edinburgh study of decision making on farms. J. Vocat. Behav. 54(1): 5-36.

Annex 1: Factor analysis on objectives of smallholder farmers

\begin{tabular}{|c|c|c|c|}
\hline \multirow[t]{2}{*}{ Objectives of farmers (Ordinal value scale*) } & \multicolumn{3}{|c|}{ Components } \\
\hline & Economic & Environmental & Socio-cultural \\
\hline Inputs in conventional farming are expensive & 0.948 & & \\
\hline To make use of Govt. facilities such as subsidy & 0.898 & & \\
\hline To achieve higher yield in OF & 0.897 & & \\
\hline Premiums on organic are strong incentives to practice OF & 0.862 & & \\
\hline To reduce the chemical fertilizers and pesticides in the farm & & 0.943 & \\
\hline Organically grown crops are resilient to drought and flood & & 0.905 & \\
\hline $\begin{array}{l}\text { To reduce the negative effects of chemicals on human being and animals in the } \\
\text { farm }\end{array}$ & & 0.855 & \\
\hline To help in conserving the environment & & 0.729 & \\
\hline OF practice brings personal satisfaction & & & 0.950 \\
\hline OF adoption prevents family health problems from chemicals & & & 0.897 \\
\hline To keep the existing socio-cultural values & & & 0.707 \\
\hline Eigen value & 3.3 & 3.0 & 2.2 \\
\hline Variance \% & 30.00 & 27.50 & 20.33 \\
\hline Total Variance \% & 30.00 & 57.50 & 77.90 \\
\hline Cronbachs Alpha & 0.710 & 0.755 & 0.716 \\
\hline
\end{tabular}

Extraction method: principal component analysis. Rotation method: Varimax with Kaiser normalization. ${ }^{*} 1=$ Not at all important and $5=$ Very important 